ARTIGOS

\section{O PAPEL DO TRANSPORTE NA LOGÍSTICA DE DISTRIBUIÇÃO: UM ESTUDO DE CASO SOBRE UMA EMPRESA DE TORREFAÇÃO E MOAGEM EM EUSÉBIO - CEARÁ ${ }^{1}$}

\section{RESUMO}

Este artigo tem como objetivo analisar o papel do transporte na logística de distribuição e os custos relacionados ao setor de logística, principalmente com foco no papel do transporte em relação a esses custos. Para esta pesquisa, foi realizada uma revisão da literatura abordando a logistica, a Supply Chain Management, bem como as operações de distribuição física e transportes. por meio de um estudo de caso realizado em uma empresa de torrefação e moagem de café, o resultado da pesquisa confirmou que o setor de transporte tem uma participação relativa para o setor de logística. A partir do estudo de caso, foi sugerido para a empresa que fosse feito um gerenciamento mais rigoroso com atenção maior nos indicadores da logística, e que, se fossem bem gerenciados, poderiam ser fatores com o potencial de minimizar os custos do transporte na distribuição.

Palavras-chave: Logística. Custos logísticos. Distribuição.

\section{INTRODUÇÃO}

A logística vem ganhando cada vez mais espaço no mercado e também dentro das organizações. Até pouco tempo, as empresas focavam sua atenção somente nos setores de produção, marketing e finanças. Hoje, as empresas devem ser capazes de identificar fatores que influenciam a eficácia da função de operação. Isso inclui os fatores de produtividade, adaptabilidade dos processos, disponibilidade de transporte, a cultura e assim por diante. A distribuição física dos produtos e o transporte devem estar diretamente interligados dando maior eficiência ao processo, garantindo a eficiência da função de logística, e essas funções devem ser integradas e gerenciadas para aperfeiçoar a estratégia do negócio e assim obter maior impacto na lucratividade da empresa.

De acordo com a revista Ilos (2011), um dos reflexos do desequilíbrio no transporte de carga é o elevado custo logístico que representa cerca de $10,3 \%$ do PIB nacional, devido à estrutura desordenada do setor e à baixa regulação e fiscalização, o custo do 
transporte rodoviário é mais do que o dobro do hidroviário e $66 \%$ maior do que o ferroviário. De acordo com Gallo et al. (2010), estão sendo realizados investimentos públicos em rodovias, e esses investimentos estão aumentando a cada ano, porém ainda são insuficientes diante das necessidades do mercado.

Os consumidores estão ficando cada vez mais exigentes, querendo produtos com mais qualidade e desejando que sempre estejam nas prateleiras dos supermercados quando forem procurados. Para isso, as empresas precisam se programar para as altas demandas. Isso implica não só a credibilidade da empresa para com o cliente, mas também a forma de como esse produto chega até o consumidor final. Por isso o setor de distribuição está relacionado diretamente ao setor de marketing e ao serviço ao cliente, pois a principal vantagem de mercado para uma empresa é ter pontualidade nos serviços de entregas. Diante destes fatores, este artigo pretende fazer um estudo de caso em uma empresa do ramo de indústria de café e verificar seus principais fatores que constituem o custo logístico.

\section{REFERENCIAL TEÓRICO}

Nesta seção será abordado o embasamento teórico que irá compor o presente artigo. Inicialmente com a logística, seu conceito e sua evolução até chegar na supply chain management, a importância e o impacto dos custos logísticos e para finalizar, a distribuição.

\subsection{LOGÍSTICA}

De acordo com Christopher (2011), a logística é o processo de gestão estratégica da aquisição, movimentação e armazenagem de materiais, peças e estoques finais por meio da organização e seus canais de comercialização.

A logística tem como objetivo principal disponibilizar produtos ou serviços oferecidos por diversas empresas, em tempo hábil e com o menor custo possível, agregando, assim, um valor esperado no preço do produto final. Nos últimos anos, o cliente tem ficado cada vez mais exigente, querendo não somente um preço baixo, mas também um produto com uma boa qualidade.

Segundo Figueiredo (2004), para um desempenho adequado da função logística, são necessários elevados investimentos e habilidades específicas que podem ser mais bem desenvolvidas por agentes especializados. Cerca de $60 \%$ dos custos de uma organização são efetivados pelo setor da logística, no qual é empregada a parte de transporte, a distribuição física e a manutenção dos veículos.

A partir das definições citadas acima, pode-se dizer que a Logística é um setor que gerencia as atividades desde a compra da matéria-prima, produção, até a distribuição física do produto, fazendo todo o planejamento, a implementação e a coordenação de todo o fluxo do produto acabado, visando a um menor custo no preço do produto final e no menor tempo possível atendendo, assim, a expectativa do cliente.

\subsection{A EVOLUÇÃO DA LOGÍSTICA ATÉ A SUPPLY CHAIN MANAGEMENT}

Quando se fala em logística, vem à tona o novo modelo de gerenciamento que vem sendo utilizado pelas empresas o Supply Chain Management. Para Figueiredo e Arkader (2007), essa nova abordagem leva em consideração o conceito da logística integrada, o qual integra todos os setores da organização, que está evoluindo rapidamente devido à globalização e os grandes avanços da tecnologia. Com o grande crescimento do mercado, os clientes estão ficando cada vez mais exigentes procurando por melhor desempenho de serviços e com o menor custo acessível. Devido à grande existência de empresas competindo em um mesmo mercado, o gerenciamento da cadeia de suprimento vem ganhando cada vez mais relevância nos grandes negócios e dando uma vantagem competitiva acirrada diante de outras empresas.

Para Ching (2010), as empresas deixaram para trás o foco de redução de perdas: diminuição das transações, redução do nível de inventário e menor custo. Elas vão utilizar 
a integração da cadeia logística para gerar melhores resultados. O foco agora é agregar valor ao cliente, melhorar a qualidade dos serviços, das funções que atendam às necessidades dos clientes e principalmente atender rapidamente o cliente desde a solicitação do pedido até a entrega do produto.

Essa nova abordagem do SCM visa integrar todos os processos da cadeia desde a escolha do fornecedor, do processo de produção até a chegada dos produtos ao cliente final. Esse novo sistema de gerenciamento está cada vez mais focado na qualidade do atendimento dos clientes. Hoje as maiorias das empresas estão trabalhando com o processo de pós-venda, para saber se o produto conseguiu atender às necessidades do cliente, qual a opinião sobre o atendimento, se ele indicaria o determinado produto e quais as sugestões que ele daria para melhorar o produto, caso seja necessário.

\subsection{CUSTOS LOGÍSTICOS}

Devido ao grande crescimento do mercado e ao aumento da concorrência, hoje a maioria das empresas trabalha para reduzir seus custos e, principalmente, os custos relacionados à logística. Mas essa é uma das principais barreiras enfrentadas pelas organizações, pois, ao mesmo tempo em que as empresas querem reduzir seus custos, elas também querem oferecer aos seus clientes níveis melhores de serviços.

De acordo com Ching (2010), os custos logísticos de uma empresa são resultantes das operações de suprimentos, conversão física e distribuição. Tais operações ajudam a empresa a agregar valor de produto para seus clientes e, deixando-a, assim, com um diferencial de mercado. Ainda para o autor, os custos logísticos representam apenas os custos de armazenagem, manuseio e movimentação de materiais além de custos com o transporte.

Conforme o autor acima, os custos estão presentes em todos os processos da logística, desde a compra da matéria prima até a entrega do produto final. E dependendo da elevação desses custos, o valor do produto final pode ser afetado, pois a empresa precisa tirar desses produtos o seu lucro final. Esses custos podem estar presentes na mão de obra, nos desperdícios de tempo e de insumos importantes para o melhor funcionamento do processo, nos problemas com equipamentos e na energia gasta com o processo de produção.

De acordo com Fleury, Wanke e Figueiredo (2013), o controle gerencial dos custos logísticos pode favorecer o aumento da eficiência nos processos internos e externos à organização. Muitas empresas se deparam com problemas no custo logístico; muitas delas não têm noção dos gastos relacionados à logística $\mathrm{e}$ acabam não conseguindo atender à alta demanda do mercado, afetando diretamente na satisfação do cliente e na participação de mercado. Hoje os clientes estão exigindo cada vez mais das empresas serviços de alta qualidade e com preço baixo.

De acordo com Livato e Souza (2010), a necessidade de apurar os custos logísticos tem exigido das empresas um esforço no sentido de desenvolver ferramentas que possam auxiliar a geração de informações para a tomada de decisões.

Hoje as maiorias das empresas buscam, para sua eficiência, melhores programas que tenham informações fidedignas para que se consiga uma tomada de decisão mais cuidadosa e que as informações sejam confiantes. Para isso, são feitos investimentos em grandes projetos de tecnologia da informação.

Contudo, os autores Fleury, Wanke e Figueiredo (2013) afirmam que o principal desafio da logística moderna é conseguir gerenciar a relação entre custo e nível de serviço.

Hoje, diante do crescimento de mercado e de muitas exigências, o preço passa a ser um fator qualificador, e o nível de serviço, um diferenciador. Os clientes não buscam apenas os preços baixos, mas querem, também, juntamente com esse preço baixo, uma qualidade dos produtos e serviços oferecidos pelas empresas. O principal foco das empresas é atender à demanda do mercado e oferecer a seus clientes produtos com maior qualidade e durabilidade.

Devido ao grande crescimento do mer- 
cado, atualmente, os clientes exigem um nível de serviço adequado e com um preço acessível no mercado. A qualidade dos produtos passou a ser, também, um fator de estrema importância para o consumidor. E todos esses fatores devem estar interligados em uma só empresa, que é o principal desafio enfrentado pelas empresas.

\subsection{DISTRIBUIÇÃO FÍSICA}

Hoje os clientes querem que um produto tenha com uma boa qualidade, que a entrega seja feita no tempo acordado e que o custo benefício seja acessível ao público. O principal objetivo da distribuição física é fazer que os produtos cheguem até o cliente final, de acordo com o prazo estimado pelo consumidor, nas melhores condições de entrega e também no melhor desempenho do serviço. Já Ching (2010) coloca que a logística de distribuição trata das relações da empresa-cliente-consumidor, sendo responsável pela distribuição física do produto acabado até os pontos de venda ao consumidor e deve assegurar que os pedidos sejam pontualmente entregues, precisos e completos.

Hoje o enfoque principal da logística é voltado para o cliente e também para atender às necessidades desse cliente. E a responsabilidade da função de distribuição física é fazer que os produtos cheguem até o consumidor prezando pela qualidade do atendimento. Para se ter uma boa vantagem competitiva, as organizações devem optar pelo melhor canal de distribuição visando não só à rápida entrega, mas também ao menor custo para fazer que esse produto chegue até ao mercado.

\subsection{TRANSPORTE}

O transporte é o principal responsável por toda atividade econômica e também pelo fluxo de movimentação de materiais desde o fornecedor até o consumidor final. Por isso, é responsável pela grande parcela dos custos logísticos dentro da maioria das empresas.

Segundo Nazário (2010, p. 127), "o transporte passa a ter um papel fundamental em vá- rias estratégias na rede logística, tornando necessária a geração de soluções que possibilitem flexibilidade e velocidade na resposta ao cliente, ao menor custo possível, gerando, assim, maior competitividade para a empresa". De acordo com o mesmo autor, o impacto do transporte no serviço ao cliente é um dos mais significativos, e as principais exigências do mercado geralmente estão ligadas à pontualidade do serviço (além do próprio tempo de viagem).

O setor de transporte não está livre dos obstáculos e, por isso, é considerado o setor que mais gera custos logísticos dentro da organização. Nos grandes portos, o principal problema é a falta de expansão, devido às necessidades ambientais e à falta de equipamentos necessários que acabam afetando sua produtividade, e a falta de investimento dos setores públicos, o que acaba afetando diretamente a funcionalidade do transporte. Altos investimentos são realizados na frota para que a empresa consiga atender às demandas do mercado, mesmo com tantos obstáculos, assim fidelizando o seu cliente.

Segundo Bowersox et al. (2014), o autor afirma que as principais dificuldades são o aumento do custo de reposição de equipamentos, a manutenção, a segurança, a falta de motoristas, a regulamentação de horário de trabalho dos caminhoneiros, os salários dos trabalhadores dos terminais e o custo de combustível. O transporte representa a maior despesa logística conforme o autor Bowersox et al. (2014), os gestores de transportes comprometem ou gerenciam mais de $60 \%$ das despesas logísticas totais de uma empresa típica. São também responsáveis pela movimentação de estoque por meio da cadeia de suprimentos de uma empresa e para clientes.

Com grande o avanço e o rápido crescimento dessas tecnologias, as empresas hoje, para ter uma logística eficiente, são obrigadas a utilizar-se das tecnologias, pois, com elas, obtém-se um planejamento mais confiável além de um controle maior sobre os processos internos, pois, através dos softwares, é possível controlar todo o processo, desde a roteirização até a entrega no cliente final, como também a 
rastreabilidade do caminhão, garantindo, assim, uma segurança maior para a empresa e uma melhor satisfação do cliente.

Diante disso, o transporte passa a ser um setor da logística que gera custos elevados para a organização. O principal fator que leva a empresa a optar por trabalhar com prestadores de serviços logísticos está relacionado à redução dos custos, então, quando a empresa passa sua operação para uma terceira, com tecnologias específicas para essa atividade, há maior qualidade dos serviços e preço baixo.

\section{METODOLOGIA}

Utilizou-se nesta etapa da pesquisa uma abordagem qualitativa. E para a análise dos resultados e a comparação da pesquisa teórica com a vivência prática, a estratégia de pesquisa utilizada neste trabalho foi a de estudo de caso. Neste trabalho, será analisado apenas um caso. Yin (2003) diz que estudo de caso é uma investigação que permite um estudo de um fenômeno contemporâneo dentro de um contexto real.

$\mathrm{O}$ estudo de caso foi realizado em uma empresa localizada no Eusébio (CE). No presente trabalho, será apresentada como 3corações. Foi realizada a aplicação dos questionários na empresa. A escolha da empresa se deu pelo fato de ser uma das empresas responsável pela produção de $22 \%$ do mercado de café, tendo uma participação de mercado relevante.

Realizou-se a coleta de dados por meio de um questionário estruturado contendo apenas questões subjetivas com os funcionários da área de transporte, distribuição e logística de fretes da empresa. Para a realização desta pesquisa, devido às limitações de acesso aos respondentes, foram entrevistados apenas 7 sujeitos, sendo 5 homens e 2 mulheres entre 25 e 51 anos de idade. Foi realizado o mesmo questionário para todos os entrevistados. Na pesquisa, os colaboradores foram identificados como colaborador 1 , sendo analista de transporte; colaborador 2, assistente de transporte; colaborador 3, analista sênior de logística; colaborador 4, supervisor de transporte; colaborador 5, analista de transporte colabo- rador 6, coordenador de transporte; colaborador 7 , supervisor de distribuição

\section{ANÁLISE DOS RESULTADOS}

Neste ponto, será apresentada a análise qualitativa dos dados coletados por meio de um questionário elaborado com questões subjetivas, em que os participantes puderam expor suas opiniões e dados relevantes para a resolução da questão de pesquisa. O questionário foi elaborado a partir dos resultados das pesquisas bibliográficas, permitindo-se, assim, a elaboração das questões contidas no questionário. A entrevista foi realizada com um grupo de 7 pessoas, 5 homens e 2 mulheres, sendo 1 coordenador de distribuição, 1 coordenador de transporte, 1 analista sênior de logística, 3 analistas de transporte e 1 assistente de transporte, todos colaboradores da empresa 3corações. Eles serão representados por números, por exemplo: colaborador 1, colaborador $2 \mathrm{e}$, assim, sucessivamente.

A primeira indagação do questionário refere-se ao tipo de distribuição feita pela empresa, se é frota própria ou terceirizada. Para responder a esta pergunta, foi considerada a frota de distribuição de todo o grupo da empresa. $\mathrm{Na}$ coleta de dados, foi apresentada uma visão geral de todas as unidades distribuídas pelo território brasileiro. As respostas dos colaboradores resultaram em uma porcentagem aproximada de $54,17 \%$ (cinquenta e sete vírgula quatorze por cento) das unidades que utilizam uma frota mista, que é intercalada com uma frota própria e a terceirização dos serviços de entregas. Segundo a visão dos colaboradores, essa utilização de terceiros depende muito do volume de vendas, em que se torna imprescindível não utilizar terceiros; e $42,85 \%$ (quarenta e dois vírgula oitenta e cinco por cento) das unidades utilizam apenas frota própria por considerarem que, se bem administrada, é mais rentável do que utilizar a terceirização dos serviços. Hoje a empresa possui 260 (duzentos e sessenta) veículos de distribuição. Deste total, cerca de $60 \%$ (sessenta por cento) dos veículos fazem a rota para interior e os outros $40 \%$ (quarenta por cento) fazem rota na capital como representa o gráfico 3 . 
Hoje, as unidades conseguem fazer cerca de 51.000 (cinquenta e uma mil) entregas durante todo o mês; são cerca de 12.750 (doze mil setecentos e cinquenta) entregas por semana. Dessas 51 mil entregas, quase $26 \%$ (vinte e seis por cento) são feitas por terceiros, o que representa cerca de 13.260 (treze mil duzentos e sessenta) entregas, e $74 \%$ delas são feitas pela frota própria, que representa cerca de 37.740 (trinta e sete mil setecentos e quarenta) entregas.

Na segunda questão da pesquisa, pergunta-se aos colaboradores se concordam com a afirmativa de que a maior parcela dos custos logísticos está relacionada com o transporte. De acordo com os participantes, todos concordam com essa afirmativa, pois, para que o processo logístico funcione adequadamente, são necessários investimentos em equipamentos, mão de obra, combustível e um nível de serviço adequado, pois, devido ao crescimento do mercado, os clientes estão cada vez mais exigentes.

$\mathrm{Na}$ terceira questão, indagou-se a porcentagem do custo da empresa que estaria voltada para o setor de transporte. Os colaboradores afirmaram que cerca de $20 \%$ a $30 \%$ dos custos da logística estão voltados para o setor de transporte e que o custo da logística no geral está em torno de $70 \%$ do custo da empresa.

Já na questão quatro, foi solicitado que os participantes da pesquisa enumerassem em grau de importância os principais fatores que elevam os custos logísticos. Observa-se que, na opinião dos colaboradores, o principal fator que mais eleva o custo logístico é o combustível, e este fator depende muito do mercado. Em segundo lugar, ficou a manutenção corretiva, pois acaba saindo muito mais caro trocar a peça danificada do que consertar para prevenir a quebra. Em terceiro lugar, a renovação da frota ganhou destaque, pois renovar uma frota de caminhões pode custar muito caro; já que a empresa optou por ter uma frota própria, esses valores acabam elevando os custos. Em quarto lugar, a terceirização também é considerada um fator que gera custos logísticos altos, pois, hoje, os clientes exigem um nível de serviço bom e de qualidade. Em quinto lugar, ficou a manutenção preventiva, que, se bem acompanhada, evita que o veículo quebre no meio da entrega, fazendo que ele fique parado por mais tempo, que se reduza a frota e que outros carros façam um percurso maior para cobrir a falta do veículo quebrado.

Outro fator que eleva o custo logístico são as locações. Atualmente, a empresa $3 c o-$ rações trabalha com carros locados contratuais pelo período de 24 meses, e esses veículos geram um custo para a empresa. $O$ fator que também compromete os custos da empresa são as taxas de licenciamento e seguro obrigatório, que são realizados em todo inicio de ano, o que representa cerca de 20 mil reais por ano, englobando os caminhões de distribuição, os veículos da diretoria e alguns automóveis próprios.

Segundo os colaboradores, os fretes não acabam afetando muito os custos da empresa, por serem usados esporadicamente, assim como os pedágios. Já alguns colaboradores abordaram outros fatores que afetam o custo, como o pessoal, pois a qualificação do profissional é necessária, e o mercado não oferece pessoas totalmente qualificadas, fazendo a empresa optar por qualificar esses profissionais, oferecendo cursos e treinamentos na área; e a gestão de pneus, considerando que os pneus para caminhões são mais caros, e a má gestão desses pneus acaba resultando em um custo elevado para o setor e um acúmulo de estoque de pneus de péssima qualidade.

$\mathrm{Na}$ quinta questão, abordou-se acerca do canal de distribuição utilizado pela empresa com o intuito de saber se ele atende prontamente a demanda do mercado em um tempo adequado para o cliente e com custo acessível para a empresa.

Hoje a empresa optou por trabalhar com o modal de distribuição, sendo ele o rodoviário e com uma frota parcialmente própria, apesar de haver custos mais elevados, é o que consegue atender à demanda do mercado atual. E na visão dos colaboradores, se a frota for bem administrada, representará um fator que pode reduzir os custos logísticos.

Aproximadamente, $86 \%$ dos participantes 
responderam que sim, que o canal de distribuição atende adequadamente a seus clientes e com custo acessível, e apenas um participante respondeu que não, que a empresa não consegue atender à demanda do mercado apenas com a frota própria, precisando sempre terceirizar o serviço.

$\mathrm{Na}$ sexta questão da pesquisa, foi perguntando se são necessários investimentos em tecnologia para melhorar o desempenho da função de logística. Segundo as respostas dos colaboradores, eles afirmaram que sim, são necessários investimentos em tecnologias para melhorar o fluxo do processo. Eles acreditam que, havendo uma tecnologia associada à logística, possibilita atender, de forma mais adequada e ágil, o mercado e com excelência nos serviços; já outros dois colaboradores disseram que não são necessários investimentos em tecnologia e, sim, em pessoas. Eles acreditam que, investindo em pessoas em termos motivacionais, incentivos e premiações, as operações logísticas passariam a ser melhores.

Dando continuidade ao questionário, na pergunta de número sete, foi questionado se os participantes concordam com uma roteirização adequada das entregas; é possível evitar desperdícios e diminuir os custos logísticos. De acordo com os participantes, eles concordam que, com uma roteirização adequada das entregas, é possível reduzir os gastos com combustível, permitindo maior controle sobre a rota e redução da quilometragem rodada.

$\mathrm{Na}$ oitava pergunta, indaga-se se existem algumas atividades chave para atingir os objetivos logísticos de custo e nível de serviços. Diante da posição dos colaboradores, existem, sim, atividades que se podem chamar de atividades chave; uma delas é a criação e o acompanhamento de indicadores, que, por meio deles, a equipe de logística terá maior controle sobre os principais gargalos que acontecem na operação. Outra atividade chave considerada pelos funcionários é que o planejamento é necessário para evitar problemas futuros e desenvolver respostas mais rápidas para os problemas que aparecerem durante a operação. Uma boa roteirização também pode contribuir para melhorar, não só os custos, mas também o nível de serviço prestado, a disponibilização da frota, o acompanhamento das manutenções. Todos esses fatores contribuem diretamente para uma melhor operação logística dentro da organização

Na nona questão, foi perguntado aos colaboradores se a distribuição física dos produtos contribui para um melhor atendimento ao cliente. Hoje o foco das organizações é o cliente. De acordo com as respostas dos colaboradores, eles concordam que uma boa distribuição garante uma participação no mercado, pois se os produtos não estiverem no local certo e na hora acordada, a empresa pode acabar perdendo a confiabilidade do cliente e por sua toda a sua clientela. A distribuição física dos produtos é apenas a formalização da compra. Se o cliente comprou um produto, a obrigação da empresa é de entregar o pedido conforme foi solicitado pelo cliente.

Na décima e última questão, foi perguntado aos participantes os tipos de tecnologias que são utilizados pela empresa para melhorar a gestão de logística. Segundo as respostas dos colaboradores, eles afirmaram que utilizam tecnologias que os assessoram para que a função da logística seja cumprida da melhor forma possível e que possam passar informações fidedignas para um controle maior. Hoje a empresa utiliza os sistemas de monitoramento via satélite, que acompanha em tempo real o tempo de cada entrega, sistema de gerenciamento de frota conhecido como guberman, em que são inseridas as informações dos veículos como chassis, renavan, controle de manutenção preventiva e corretiva. O sistema WMS, que controla a capacidade dos armazéns R/3 é uma ferramenta do sistema SAP, que permite que a empresa tenha um melhor planejamento e controle do negócio. Sistema de geocodificação de clientes, sistema de acompanhamento e gerenciamento de desempenho de combustível da frota.

Diante das questões apresentadas e especificadas acima, percebe-se que a logística deve ser considerada um setor de suma importância dentro da organização. Quando bem gerenciada, ela reduz os custos e garante sua eficiência. A utilização de ferramentas pode, sim, contribuir 
para melhorar sua função, e juntamente com essas ferramentas, ter uma boa distribuição física, tendo uma roteirização adequada das entregas e um bom atendimento. Eles juntos garantem que o cliente se sinta satisfeito com atendimento.

\section{CONSIDERAÇÕES FINAIS}

No presente estudo de caso, foi realizada a pesquisa nos setores de transporte, distribuição e logística de fretes. Diante das perguntas elaboradas, as respostas obtidas foram satisfatórias. E os principais problemas identificados no decorrer da pesquisa deste trabalho é que os principais fatores que os colaboradores apontaram como maiores responsáveis pela elevação do custo logístico são: Combustível: por ser um fator que não depende da empresa e, sim, do mercado, o combustível acaba sendo um dos maiores problemas em relação ao custo logístico de transporte; Manutenção corretiva: hoje a empresa gasta mais com uma manutenção corretiva. $\mathrm{O}$ principal problema dessas manutenções corretivas é que a preventiva não é acompanhada para evitar problemas maiores; Renovação da frota: apesar de a empresa realizar essa renovação da frota a cada 3 anos, é gerado um custo elevado durante o ano de renovação, pois o preço de mercado também é elevado; Terceirização: hoje cerca de $26 \%$ das entregas realizadas pela empresa são feitas por terceiros. Devido a grande demanda, é imprescindível não utilizar a terceirização dos serviços; Manutenção preventiva: um preço não muito elevado, mas em consideração da quantidade de veículo que a empresa possui, acaba deixando um valor abusivo; Locação: a empresa trabalha com locação de veículos contratuais de 24 meses, o que acaba elevando os custos, mensalmente; Fretes extras: sempre que necessário são solicitados fretes extras, para cobrir algum problema ocorrido com os caminhões da empresa, quando não se tem transporte disponível para a rota, além da terceirização também são solicitados fretes extras; Outros: os colaboradores citaram que, além dos fatores citados acima, outros problemas também podem ser considerados, como gargalos operacionais, que podem acabar atrapalhando o fluxo de informações, gerando um caos e desperdícios de tempo. Pessoas também foram consideradas, pois a falta de qualificação da mão de obra pode acabar criando erros operacionais e elevando os custos da empresa.

Tais fatores listados acima são apenas os principais problemas enfrentados pela logística e a corrida contra a redução de custos do setor de transporte. Esses efeitos operacionais mostram apenas o quanto a empresa fica vulnerável aos gargalos que aparecem, pois o que acaba acontecendo é que os colaboradores têm que "apagar o fogo" e não prevenir o incêndio. Muitas vezes, pela falta de gerenciamento dos indicadores, a empresa acaba arcando com os custos operacionais que poderiam ter sido evitados.

Atualmente, a empresa utiliza várias ferramentas de tecnologia da informação para conseguir prevenir alguns erros operacionais, entre eles estão: sistemas de roteirização das entregas, o que contribui bastante para a redução de tempo na rota, redução de quilômetros rodados que por sua vez reduz o gasto de combustível. A empresa possui indicadores em que um profissional se dedica ao gerenciamento do combustível. Ele utiliza um sistema de uma empresa terceirizada, que gerencia todo o combustível do grupo, por meio do qual esse colaborador consegue parametrizar o valor máximo em reais, permitindo, assim, que ele acompanhe as médias de valores que estão sendo oferecidos pelo mercado. Tendo essas informações, o colaborador consegue negociar tendo o poder de barganha em relação ao preço do combustível, tornando-se assim um cliente fidelizado do posto. Com isso, torna-se cada vez mais clara a necessidade de gerenciar o custo logístico com o transporte, garantindo sua redução e o aproveitamento para investimento em outros projetos da empresa. Em relação aos objetivos estipulados neste trabalho e a sua confirmação, tende-se às seguintes colocações nos parágrafos a seguir.

O transporte, se bem gerenciado, ele pode oferecer a empresa uma redução dos custos com a frota, garantir que as entregas sejam realizadas da melhor forma possível e assim dando a empresa margem para novos investimentos na 
área, melhorando sua qualidade dos produtos e investimentos em melhorias estratégicas para estar sempre à frente da concorrência.

Diante da pesquisa, foi sugerido para a empresa que fosse realizada um acompanhamento mais rigoroso nos indicadores, como: combustível, dispersão entre uma entrega e outra e tempo de rota, roteirização mais adequada das entregas, pois, assim, o setor de transporte conseguirá ter um controle maior dos custos e poderá reduzi-los.

\section{THE ROLE OF TRANSPORTATION IN DISTRIBUTION LOGISTICS: A CASE STUDY OF A ROASTING AND GRINDING COMPANY IN EUSEBIO - CEARÁ}

This article aims to analyze the role of transport in distribution logistics and costs related to the logistics industry, mainly focusing on the role of transport in relation to these costs. For this research, a literature review was carried out covering the logistics, the supply chain management as well as the physical distribution and transportation operations. through a case study in a roasting and grinding coffee company, the result of the survey confirmed that the transport sector has a relative share for the logistics industry. From the case study, it was suggested to the company that was made more rigorous management with greater attention to logistics indicators and that, if well managed, could be factors with the potential to minimize transport costs in the distribution.

Keywords: Logistics. Logistics costs. Distribution.

1 Artigo apresentado ao XXII SIMPEP - Simpósio de Engenharia de Produção, no ano de 2015, em Baurú - São Paulo. Autora: Larisse Oliveira Costa.

\section{REFERÊNCIAS}

BOWERSOX, Donald J. et al. Gestão logística da cadeia de suprimentos. 4. ed. Porto Alegre: AMGH, 2014.
CHING, Hong Yuh. Gestão de estoques na cadeia de logística integrada: supply chain. 4. ed. São Paulo: Atlas, 2010.

CHRISTOPHER, Martin. Logística e gerenciamento da cadeia de suprimentos. São Paulo: Cengage Learning, 2011.

FIGUEIREDO, Kleber. A logística e a fidelização de clientes. Rio de Janeiro: UFRJ, 2004. Disponível em: <http://www.cel-coppead.com. br>. Acesso em: 27 jul. 2015.

FIGUEIREDO, K.; ARKADER, R. Da distribuição física ao supply chain management: o pensamento, o ensino e as necessidades de capacitação em logística. 2007. Disponível em: < https://www.google.com. $\mathrm{br} / \mathrm{url}$ ? $\mathrm{sa}=\mathrm{t} \& \mathrm{rct}=\mathrm{j} \& \mathrm{q}=\&$ esrc $=\mathrm{s} \&$ source $=\mathrm{we}-$ b\&cd=2\&ved=0ahUKEwiuktfTxeDKAhVKGJAKHYPTA0AQFgguMAE\&url=http $\% 3 \mathrm{~A} \% 2 \mathrm{~F} \% 2 \mathrm{Fww}$.rs lima.unifei.edu. br\%2Fdownload1\%2FAdm09\%2F98_Ago_ Kleber\%2520e\%2520Rebecca_Da\%2520Distribuicao\%2520Fisica\%2520ao\%2520Supply\%2520Chain \%2520 Management. pdf\&usg=AFQjCNF820ggeXgJjO22Q4h3Mx49EYNrIw\&sig2=ELJ2GZqdA7RbOJ2kDSSePA\&ca$\mathrm{d}=\mathrm{rja}>$. Acesso em: 27 jun. 2015.

FLEURY, Paulo Fernando; WANKE, Peter; FIGUEIREDO, Kleber Fossati. Logística empresarial: a perspectiva brasileira. São Paulo: Atlas, 2013.

GALLO, Adriano et al. O sistema logístico brasileiro. Revista Científica do ITPAC, Tocantis, v. 3, n. 3, p. 21-35, 2010.

ILOS. Transporte de carga. 2011. Disponível em: <http://www.ilos.com.br/web>. Acesso em: 22 jun. 2015.

LIVATO, Marcos; SOUZA, Alexandre Pedro Machado de. Gestão de Custos Logísticos na Cadeia de Suprimentos: um estudo sobre o custo de transporte de cargas. In: ENCONTRO 
NACIONAL DE ENGENHARIA DE PRODUÇÃO, 30., 2010, São Paulo. Anais... São Paulo: ENEGEP, 2010.

NAZÁRIO, Paulo. O papel do transporte na estratégia Logística. In: FLEURY, Paulo Fernando; WANKE, Peter; FIGUEIREDO, Kleber Fossati. Logística empresarial: perspectiva brasileira. São Paulo: Atlas, 2010.

YIN, Robert K. Estudo de caso, planejamento e métodos. 2. ed. Porto Alegre: Bookman, 2003. 